\title{
Wilsons Disease Presenting as Acute Fulminant Hepatic Failure
}

\author{
Kolluru Karthik Rajaํ, Sourya Acharya², Anil Inamdar³, Sunil Kumar \\ 1,2,3 Department of Medicine, Datta Meghe Institute of Medical Sciences (Deemed to Be University), \\ Wardha, Maharashtra, Indi. ${ }^{4}$ Department of Pathology, Datta Meghe Institute of Medical Sciences \\ (Deemed to Be University), Wardha, Maharashtra, India.
}

\section{INTRODUCTION}

Wilson's disease (WD) is a genetic disorder characterised by mutations in copper metabolism. Adenosine triphosphate (ATPase) ATP7B gene is responsible for disturbance in copper metabolism that leads to accumulation of copper mainly in liver and also in extra hepatic organs (like brain, cornea, heart and kidney). ${ }^{1}$ Heavy metal accumulation in brain (mainly in basal ganglia) leads to neuropsychiatric manifestations. ${ }^{2}$ Kayser Fleischer (KF) ring is golden brown ring distributed along the periphery of cornea. It is due to abnormal deposition of copper in the Descemet's membrane of cornea. Kayser Fleischer (KF) ring is a pathognomonic sign of Wilson's disease. Fulminant hepatic failure can be the first presentation of WD. Patients presenting with fulminant Wilson's disease (FWD) clinically present as acute liver failure with encephalopathy and coagulopathy. The mortality of patients is high and orthotropic liver transplantation is the only option, which has been shown effective in patients with Fulminant Wilson's disease. ${ }^{3}$ We are report a case of a young male who presented as acute liver failure first time in life and later was diagnosed as FWD.

\section{PRESENTATION OF CASE}

A 19-years-old male patient presented to us with complaints of yellowish discoloration of sclera and loss of appetite for 15 days, altered sensorium for 3 days and haematemesis ( 4 episodes) for 1 day. There was no history of nausea, melena, pain in abdomen, distension of abdomen or fever. He was non-alcoholic and nonsmoker. On examination - pulse 112 bpm, BP: 110 / 80 mm of Hg supine and 92 / 74 $\mathrm{mm}$ of $\mathrm{Hg}$ standing for 3 minutes. Deep icterus was present along with KayserFleischer ring which was clearly visible in naked eye which was later confirmed by slit lamp examination. (Figure 1). Following investigations were done. Hb: 8.4 gram \%, WBC: 3500 / mm, ${ }^{3}$ platelets: 0.51 / mm, ${ }^{3}$ ALP: 30 IU, total bilirubin: $17.4 \mathrm{mg} / \mathrm{dL}$, conjugated bilirubin: $14.2 \mathrm{mg} / \mathrm{dL}$, unconjugated bilirubin: $3.2 \mathrm{mg} / \mathrm{dL}$, AST: $280 \mathrm{IU}$ / L, ALT: 52IU / L, albumin: $1.9 \mathrm{mg} / \mathrm{dL}$, serum ammonia: $191 \mu$ / dL, prothrombin time - 52 seconds / INR: 5.08, LDH: 800 IU, Coomb's test was negative, 24 hours urinary copper: $3.2 \mu \mathrm{mol} / 24 \mathrm{~h}$ (normal 1.5 micromol). Serum ceruloplasmin - $9 \mathrm{mg}$ / dl (normal: 20 - $40 \mathrm{mg}$ / dl). HBs Ag, Ig M anti HBC, Ig M HAV, were negative. KFT was normal. Nazer index was 7.

\section{DISCUSSION OF MANAGEMENT}

Patient was treated with intravenous glutathione, fresh frozen plasma (FFP) transfusions, intravenous dextrose, lactulose enemas, oral lactulose solution, tab rifaximin $550 \mathrm{mg} \mathrm{BD}$, tab trientine $250 \mathrm{mg} 4$ times a day (QID), zinc $50 \mathrm{mg} 3$ times a day (TDS) and other supportive management. The patient gradually recovered over next 2 weeks and was discharged.
Corresponding Author:

Sourya Acharya,

Professor,

Department of Medicine,

Datta Meghe Institute of Medical Sciences (Deemed to Be University),

Wardha, Maharashtra, India.

E-mail: souryaacharya72@gmail.com

DOI: $10.14260 /$ jemds/2021/253

How to Cite This Article:

Raja KK, Acharya S, Inamdar A, et al. Wilsons disease presenting as acute fulminant hepatitis failure. J Evolution Med Dent Sci 2021;10(16):1185-1186, DOI: $10.14260 /$ jemds $/ 2021 / 253$

Submission 19-10-2020,

Peer Review 12-02-2021,

Acceptance 19-02-2021,

Published 19-04-2021.

Copyright (c) 2021 Kolluru Karthik Raja et al. This is an open access article distributed under Creative Commons Attribution License [Attribution 4.0 International (CC BY 4.0)] 


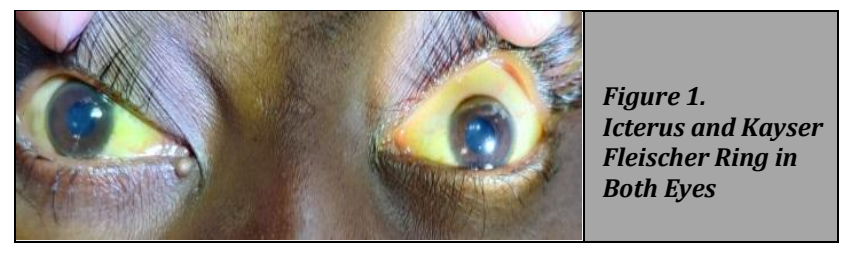

\section{DISCUSSION}

"Acute liver failure" is characterised by coagulopathy and any grade of hepatic encephalopathy in the absence of any prediagnosed liver disease.

Diagnosis of Wilson's disease is based on -

- Low serum-ceruloplasmin level $(<20 \mathrm{mg} / \mathrm{dL})$.

- $\quad$ Presence of KF ring in cornea.

- Hepatic copper content $(250 \mu \mathrm{g} / 24 \mathrm{~h})$.

FWD is characterised by acute liver failure in a case of WD. It may be the primary presentation of WD even if it is often not considered in the WD spectrum of manifestations. 4,5,6,7 A study has suggested that WD should be excluded in any patient who presents with acute liver failure. ${ }^{8}$

Nazar et al. described a prognostic index in FWD where the treatment modalities have been noted. The index takes into account a scoring system (in a scale of $0-4$ ) based on serum bilirubin, prothrombin time, serum aspartate transaminase (AST). A score $<7$ requires medical management, score from 7 - 9 requires medical versus liver transplant according to clinical course, and a score $>9$ requires orthoptic liver transplant.9

Berman et al. identified a ratio of alkaline phosphatase to total bilirubin $<2.0$ and an AST to alanine aminotransferase (ALT) ratio $>4.0$ for the diagnosis of fulminant Wilson's disease. ${ }^{10}$

Treatment of fulminant Wilson's disease includes conservative management and orthotopic liver transplantation when deemed necessary. Conservative management includes copper chelators (D-penicillamine, trientine and tetrathiomolybdate), zinc salts and dietary elimination of copper rich food (organ meats, oysters, nuts, seeds) but, most of patients require liver transplantation in cases of FWD.

In our case diagnosis of fulminant Wilson's disease was made on the basis of presence of KF ring, decreased serum ceruloplasmin, increased 24-hour urinary copper, evidence of haemolysis, coombs negative haemolytic anemia and acute liver failure increased urinary copper excretion along with acute liver failure. Our patient had a Nazer score of 7 and responded to conservative management. High index of suspicion for Wilson's disease is required in patients with acute liver failure.

Financial or other competing interests: None.

Disclosure forms provided by the authors are available with the full text of this article at jemds.com.

\section{REFERENCES}

[1] Kaur H, Kaur K, Sharma N, et al. Wilson's disease: a case report. International Journal of Contemporary Medical Research 2019;6(7):G42-4.

[2] Guerrero-Jiménez M, Calahorro CMCA, Rojas LG. Wilson disease and psychiatric symptoms: a brief case report. Gen Psychiatr 2019;32(3):e100066.

[3] Eisenbach C, Sieg O, Stremmel W, et al. Diagnostic criteria for acute liver failure due to Wilson disease. World J Gastroenterol 2007;13(11):1711-4.

[4] Acharya N, Samal S, Sunilkumar, et al. Pregnancy with Wilson's disease complicated with thrombocytopenia: a case report. Int J Adv Med 2014;1(2):155-7.

[5] Barnes S, Hurst EW. Hepato-lenticular degeneration. Brain 1925;48(3):279-333.

[6] Hamlyn AN, Gollan JL, Douglas AP, et al. Fulminant Wilson's disease with haemolysis and renal failure: copper studies and assessment of dialysis regimens. $\mathrm{Br}$ Med J 1977;2(6088):660-3.

[7] Adler R, Mahnovski V, Heuser ET, et al. Fulminant hepatitis: a presentation of Wilson's disease. Am J Dis Child 1977;131(8):870-2.

[8] Sternlieb I. Diagnosis of Wilson's disease. Gastroenterology 1978;74(4):787-9.

[9] Nazer H, Ede RJ, Mowat AP, et al. Wilson's disease: clinical presentation and use of prognostic index. Gut 1986;27(11):1377-81.

[10] Berman DH, Leventhal RI, Gavaler JS, et al. Clinical differentiation of fulminant Wilsonian hepatitis from other causes of hepatic failure. Gastroenterology 1991;100(4):1129-34. 